\title{
A NEW CONFIGURATION FOR UNINTERRUPTED POWER IN ISOLATED LOCATIONS: WIND TURBINE - ELECTRIC GENERATOR - BATTERY BANK (WT-UPS)
}

\author{
Fernández, H. ${ }^{1}$, Martínez, A. ${ }^{2}$ Guzmán V. ${ }^{3}$ y Giménez M. ${ }^{3}$ \\ ${ }^{1}$ Universidad Nacional Experimental Politécnica "Antonio José de Sucre" \\ Vice Rectorado Puerto Ordaz, Departamento de Electrónica. Venezuela. \\ hfernandez@poz.unexpo.edu.ve \\ ${ }^{2}$ Universidad de Zaragoza, Centro Politécnico Superior de Ingenieros. España \\ amiturbe@posta.unizar.es \\ ${ }^{3}$ Universidad Simón Bolívar, Departamento de Electrónica y Circuitos, Venezuela. \\ vguzman@usb.ve - mgimenez@usb.ve
}

\begin{abstract}
A new configuration is presented to investigate the use of renewable energy sources, such as wind energy, an auxiliary thermo-electric generator and a battery bank, to feed critical loads in isolated locations in less developed areas, where no electric supply is available. Where possible standard off-the-shelf car parts such as alternators and AVR are used. This configuration, called Wind Turbine Uninterruptible Power Supply (WT-UPS) is a modular system that offers a number of advantages over the classic hybrid systems. Initial experimental results show the system works as predicted.
\end{abstract}

Key words: wind turbine, cogenerating renewable systems, ferro-resonant transformer and special uninterruptible power supply.

\section{INTRODUCTION}

Uninterruptible power supply systems combine different independent energy sources to ensure continued operation of critical loads. In the system presented in this work, a Wind Turbine Uninterruptible Power Supply (WT-UPS), two primary energy sources, one renewable (a wind turbine driven electric generator) and one traditional (an internal combustion driven electric generator) are used, in combination with a temporary storage system (a battery bank), to provide AC electric power to a critical load. Using the same hardware two operating strategies are possible [1]:

- Integrated Renewable Energy Hybrid Systems for isolated locations (IREHS).

- Cogenerating Renewable Systems for non-isolated locations (CRES).
In this work an IREHS application is considered and the main power source is the wind turbine, the internal combustion engine being used only to supply the critical load when the wind velocity is not high enough to operate the main (wind-driven) generator and the charge stored in the battery bank is exhausted. Also, since the equipment is intended to be used and maintained in isolated locations in less developed countries, where the production facilities will also be located, as much as possible is made of offthe-shelf car parts, mainly alternators and AVR (automatic voltage regulators) since they are rugged, relatively inexpensive and locally available. Also, local expertise in the maintenance and repair of these equipments is usually available, and it is possible to train these personnel to service the WT-UPS. A car alternator is used as the main wind-driven generator and, in a follow-up development, another alternator will be used as the auxiliary, combustion-engine driven generator. To increase simplicity and fault tolerance, a simple unregulated square-wave inverter driving a ferro-resonant transformer is used to produce the required $120 \mathrm{Vrms}$ single phase AC output. When it is necessary to transfer the load from the main (wind-driven or battery fed) AC output to the auxiliary one, a PLL circuit is used to lock the transformer output with the auxiliary AC generator, before the transfer switch is activated. This ensures a transient free load transfer.

\section{SYSTEM DESCRIPTION}

Figure 1 shows a complete block diagram of the proposed WT-UPS system. The main building blocks are the wind generator, the solid state power conversion block, the battery bank, the auxiliary electric generator and the regulation and control circuits controlling the operation of 


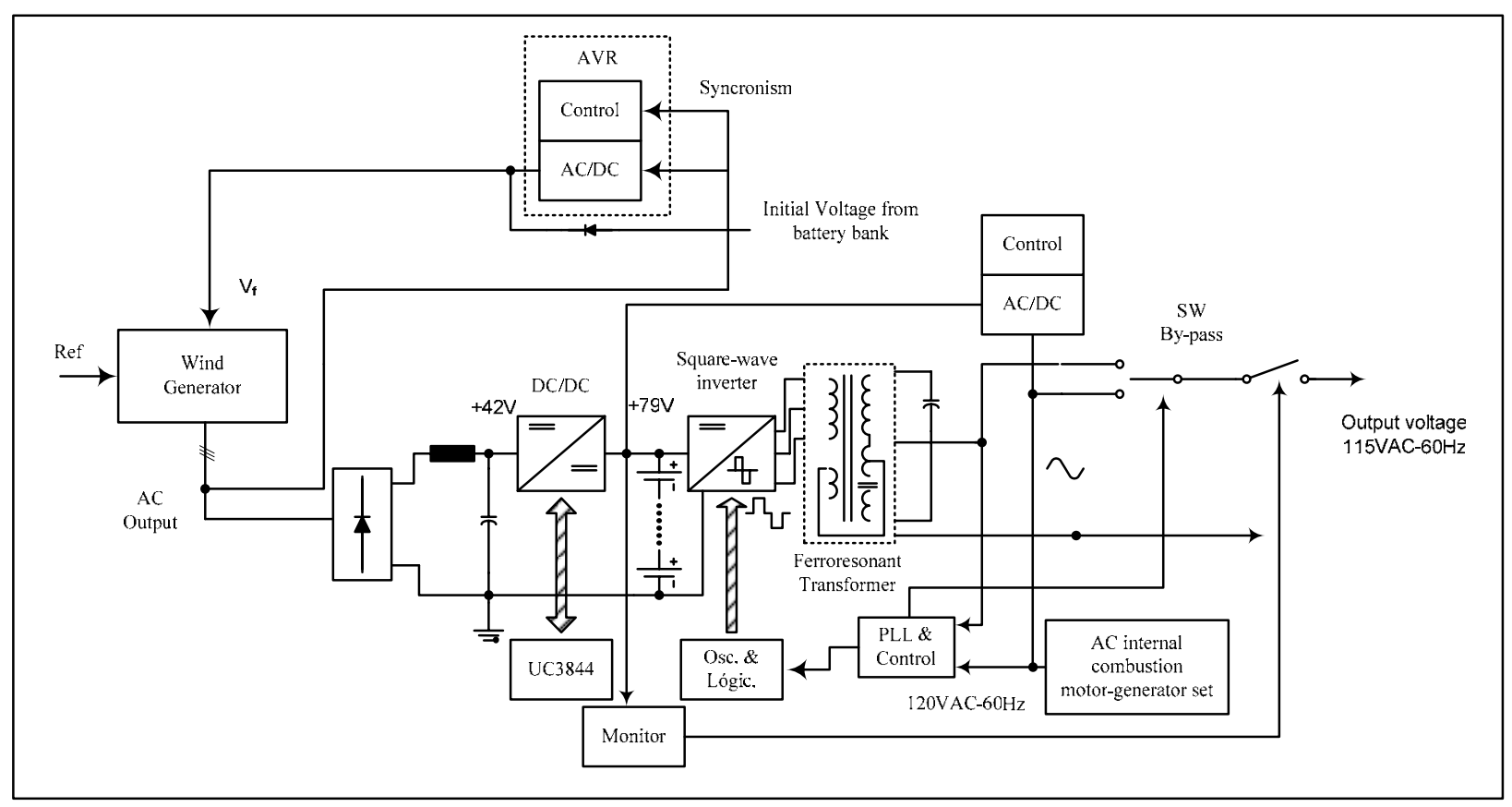

the various energy sources as an uninterrupted AC power supply.

In normal operation the wind drives the WT-UPS main generator, which is a car alternator. The main generator output is connected to an uncontrolled three-phase rectifier and an LC filter, providing a low-ripple dc output. The alternator AVR (automatic voltage regulator) ensures that the dc level is constant when the wind turbine is operational.

The filtered dc output is fed to a DC/DC converter with a $79 \mathrm{~V} \mathrm{dc}$ output level. This stage is included in order to optimize both the battery bank and the output inverter design. It also gives a degree of flexibility to the overall design, since it allows for the use of alternators of different output voltages.

To keep system complexity down and increase fault tolerance, a simple square-wave inverter connected to a ferro-resonant transformer (FRT) is used to generate the $\mathrm{AC}$ output, the transformer providing voltage regulation and a degree of overload and over voltage protection to the solid state power electronic components.

In normal operation, when the wind velocity is enough to operate the wind turbine, the battery bank is keep charged, and all output energy is wind provided. When wind speed falls below the generating minimum, the alternator output is no longer sufficient (or actually goes to zero) to keep the $\mathrm{DC} / \mathrm{DC}$ converter operative, but no output interruption takes place, since the floating battery bank takes over, feeding the inverter. Since the inverter square-wave amplitude is not regulated, output amplitude will fall as the battery bank is discharged, but output AC level remains constant as long as the FRT is saturated.

In this operating mode, back-up time at maximum output load is a function of battery bank size. When the battery bank is reaching its discharged level, the control system stars the internal combustion engine, driving the second (auxiliary) electric generator in the WT-UPS system. This generator takes over the output load until wind velocity recovers and the main wind turbine generator is able to provide the required energy. At this moment the control system stops the auxiliary internal combustion engine and the system returns to the normal operating mode.

Two different approaches are possible to integrate the motor-generator set into the WT-UPS. If the auxiliary generator, as the main generator, is a car alternator, the electrical connection will be made at the low voltage dc bus level, and the DC/DC converter, square wave inverter and FRT will be in use when the auxiliary generator is active, providing the AC output as described before. In this case no additional control hardware is necessary to regulate the transition between the battery bank and the auxiliary generator.

Otherwise, as shown in fig. 1, an off-the shelf commercial AC internal combustion motor-generator set can be connected to the load at the FRT output using a transfer switch. In this case, to eliminate transients when the motor-driven AC generator takes over, a PLL circuit is used to lock the inverter output to the $\mathrm{AC}$ generator output before the transfer switch is activated, transferring the AC load to the auxiliary AC generator. In this configuration the DC/DC converter and the 
square wave inverter are inactive once the internal combustion engine is driving the critical load. Also, as shown in fig. 1 , an auxiliary $\mathrm{AC} / \mathrm{DC}$ converter can be fed from the auxiliary AC generator to load the battery bank if desired.

\section{DESIGN CONSIDERATIONS}

\section{1- The ferro-resonant transformer.}

The FRT was chosen due to its main advantages: AC voltage regulation, $150 \%$ overload capacity, high level galvanic isolation between input and output. Figure 2 shows the FRT simplified circuit model [10]-[11].

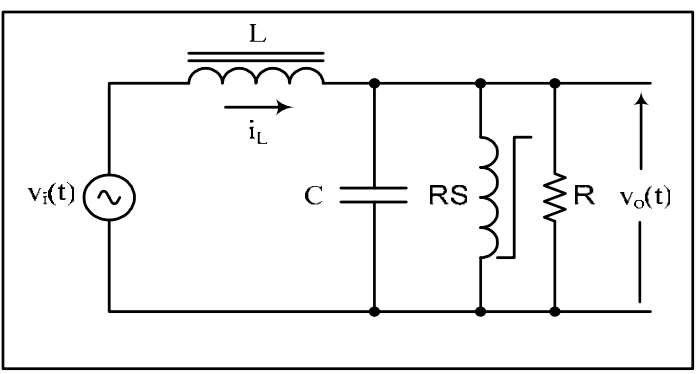

Fig.2 FRT simplified circuit model.

Taking into account input inductor current, $i_{L}$, capacitor voltage, $v_{O}$ and magnetic flux, $\Phi$, in the saturated reactor, RS, FRT state equations are:

Voltage equation:

$$
\frac{d i_{l}}{d t}=\frac{v_{i}}{L}-\frac{v_{o}}{L}
$$

Current equation:

$$
\begin{aligned}
& \frac{d v_{o}}{d t}=\frac{i_{L}}{C}-\frac{v_{o}}{R C}-\frac{f(\phi)}{n C} \\
& f(\phi)=n i_{R S}
\end{aligned}
$$

Flux equation:

$$
\begin{gathered}
\frac{d \phi}{d t}=\frac{v_{o}}{n} \square 10^{-8} \\
\left(\begin{array}{c}
\dot{i_{L}} \\
\dot{v_{o}} \\
\dot{\phi}
\end{array}\right)=\left(\begin{array}{ccc}
0 & -\frac{1}{L} & 0 \\
\frac{1}{C} & -\frac{1}{R C} & 0 \\
0 & \frac{10^{8}}{n} & 0
\end{array}\right)\left(\begin{array}{l}
i_{L} \\
v_{o} \\
\phi
\end{array}\right)+\left(\begin{array}{c}
0 \\
-\frac{1}{n C} \\
0
\end{array}\right) f(\phi)+\left(\begin{array}{c}
\frac{1}{L} \\
0 \\
0
\end{array}\right) v_{i}(4)
\end{gathered}
$$

where $\Phi, f(\Phi), i_{L}, v_{i}$ and $v_{o}$ are time-dependant functions.

\section{2- Output synchronization.}

A PLL circuit is used to lock in phase the inverter square-wave with the $\mathrm{AC}$ generator output, in order to reduce $\mathrm{dv} / \mathrm{dt}$ transients when the load is switched from the FRT to the AC generator and back. A second order PLL circuit is used, with a filter transfer function given by:

$$
F(s)=\frac{\left(1+s \tau_{2}\right)}{\left(1+s \tau_{1}\right)}
$$

Taking into account the phase detector, the voltage controlled oscillator and the amplifier, the time domain equation is:

$\tau_{1} \frac{d^{2} \phi_{o}}{d t^{2}}+\left(1+K \tau_{2}\right) \frac{d \phi_{o}}{d t}+K \phi_{o}(t)=K \tau_{2} \frac{d \phi_{i}}{d t}+K \phi_{i}(t)$

where $\tau 1, \tau 2$ are the filter parameters and $\mathrm{K}$ is the effective PLL loop gain.

\section{3- Battery charging block.}

Figure 3 shows the circuitry used to charge the battery bank from the auxiliary AC generator.

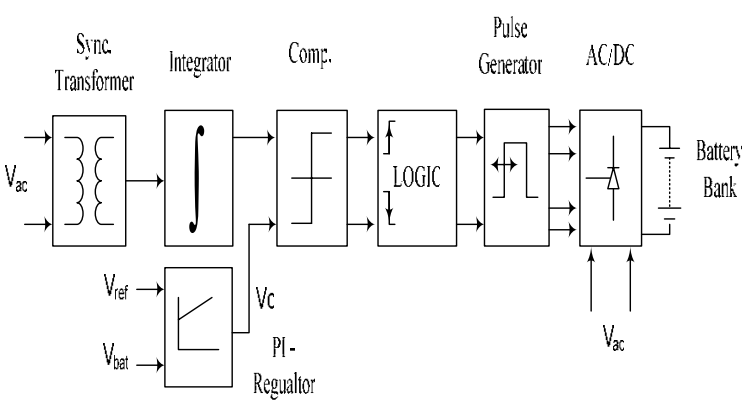

Fig.3 Battery charging circuit block diagram.

The battery charging block transfer function in matrix form is given by:

$$
V d c=0.45 \cdot V a c \cdot\left(1+\frac{27 R \cdot\left(I_{p v}-I_{s p}\right)+\frac{1}{10 C} \cdot \int\left(I_{p v}-I_{s p}\right) \cdot d(t)-V_{C}(0)}{V p}\right)
$$

where $V_{d c}$ is the controlled rectifier output voltage, $I_{p v}$ is a control current directly proportional to the battery voltage, $I_{\mathrm{sp}}$ is a control current directly proportional to the reference voltage, $\mathrm{V}_{\mathrm{p}}$ is the AC supply peak voltage, 
$\mathrm{V}_{\mathrm{c}}$ is the initial voltage value in the PI regulator capacitor and $\mathrm{C}$ is the capacitor value.

\section{INITIAL EXPERIMENTAL SET-UP SIMPLIFICATION}

For laboratory testing purposes, the wind turbine generator is replaced by an inverter-fed $\mathrm{AC}$ motor driving a synchronous $\mathrm{AC}$ motor. This set is controlled to emulate car alternators of up to $42 \mathrm{~V}$ output driven by different wind patterns [5]-[9]. Also, to avoid unnecessary noise and exhaust management problems in the electronics laboratory, the AC internal combustion motor-generator set has being replaced with a AC source derived from the main supply. These changes do not reduce the validity of the experimental set-up for testing the different electronic blocks, but greatly reduce overall testing cost and mechanical complexity.

\section{RESULTS}

Figure 4 shows WT-UPS output connected to an inductive load. Both current and voltage waveforms are sinusoidal, and their quality is confirmed by the spectral analysis presented in figure 5 .

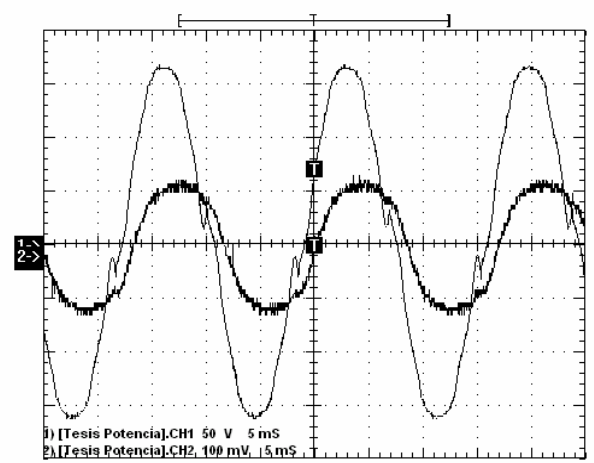

Fig.4 WT-UPS current and voltage output waveforms, inductive loads operation.

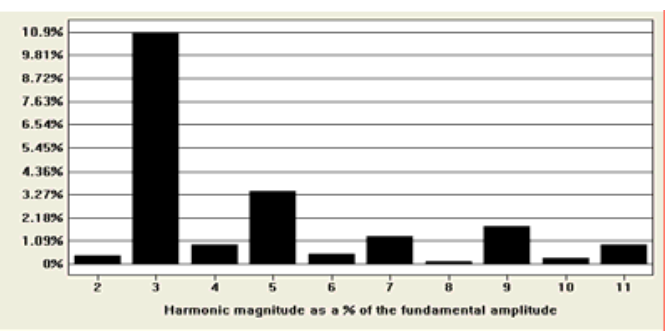

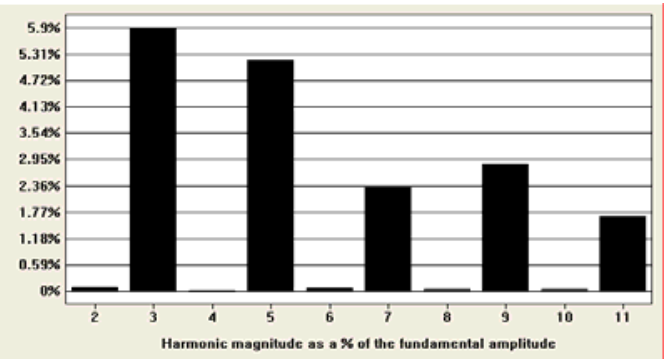

Fig.5 WT-UPS output harmonic spectra, inductive load. Current output (upper chart). Voltage output (lower chart).
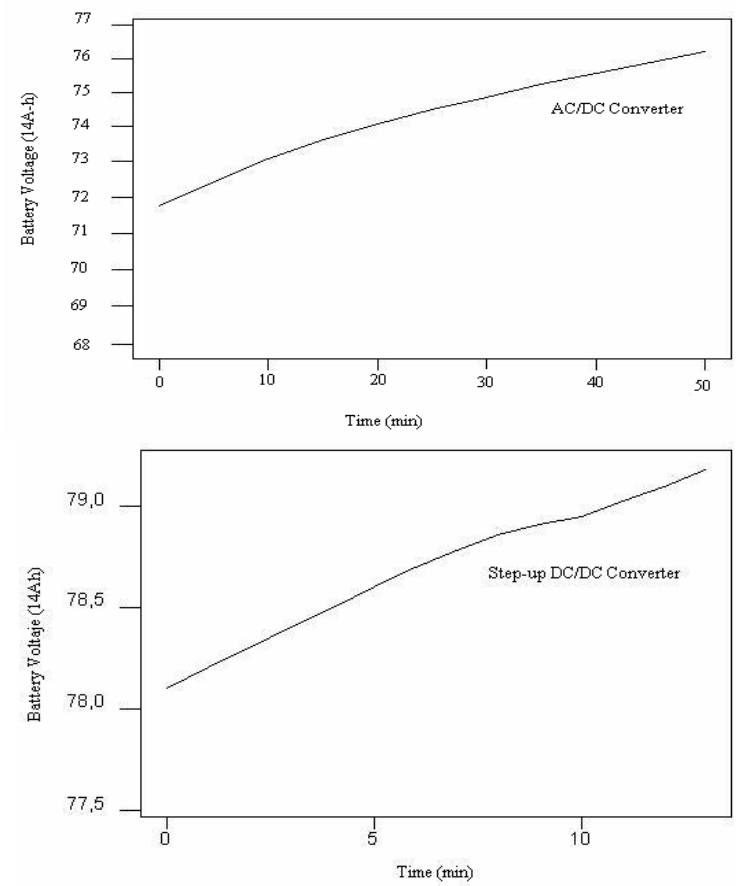

Fig.6 Battery bank charging process, $14 \mathrm{~A} / \mathrm{h}$ battery bank. Upper graph: Charging from the AC/DC converter. Lower graph: Charging from the DC/DC converter.

Figures 6 and 7 show different aspects of the battery bank charging process from deep discharge to fully charged. Fig. 6 compares battery charging with the $\mathrm{AD} / \mathrm{DC}$ and the $\mathrm{DC} / \mathrm{DC}$ converters. The upper graph shows the battery bank being charged by the auxiliary AC supply via the AC/DC converter when the simulated wind turbine is idle. The lower graph shows the battery bank being charged by the DC/DC converter output when the simulated wind turbine is operational. A 14 $\mathrm{A} / \mathrm{h}$ battery bank was used in these tests. 


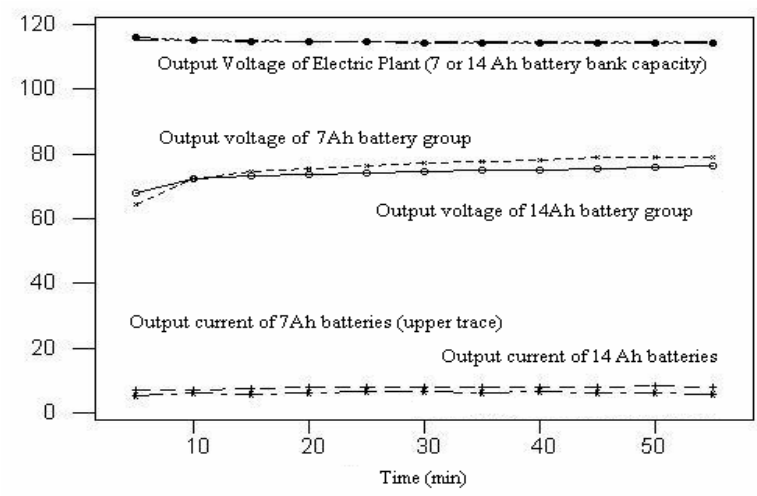

Fig.7 Battery bank charging process. Continuous line: 14 $\mathrm{A} / \mathrm{h}$ battery bank. Dotted line: $7 \mathrm{~A} / \mathrm{h}$ battery bank.

Fig. 7 compares the charging of a $7 \mathrm{~A} / \mathrm{h}$ and a $14 \mathrm{~A} / \mathrm{h}$ battery banks from the AC/DC converter when the simulated wind turbine is idle. No significant differences between the two charging alternatives are observed, and the two different battery banks can be used without problems from the charging point of view.

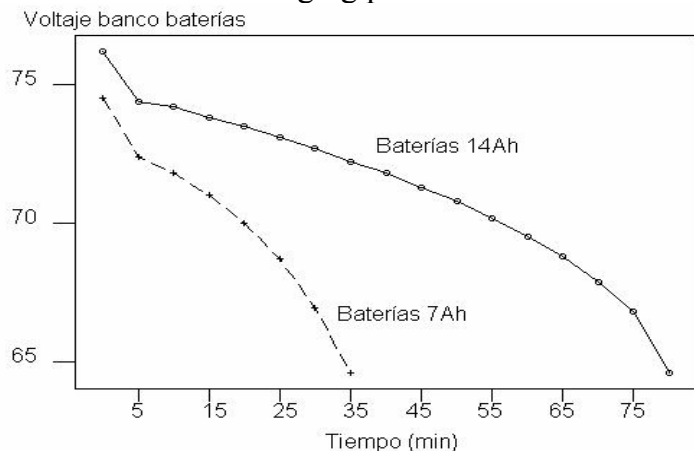

Fig.8 Battery bank discharging process, $100 \Omega$ load.

Continuous line: $14 \mathrm{~A} / \mathrm{h}$ battery bank. Dotted line: $7 \mathrm{~A} / \mathrm{h}$ battery bank.

Figure 8 compares discharge rates for the 7 and $14 \mathrm{~A} / \mathrm{h}$ battery banks, when the WT-UPS is loaded with a standard $100 \Omega$ load. Measured discharge time from $72 \mathrm{~V}$ was 35 minutes for the $7 \mathrm{~A} / \mathrm{h}$ battery bank and 77 minutes for the $14 \mathrm{~A} / \mathrm{h}$ battery bank.

Figure 9 shows the system response during when the load is transferred from the inverter output to the output of the AC generator driven by the internal combustion engine. The upper trace presents the commutation transient when the load is switched from the AC generator to the inverter. Although a small voltage reduction is observed at the load terminals, there is no a dangerous voltage gradient.

The lower trace presents the commutation from the inverter output to the AC generator. In this case no load voltage variation can be observed, due to the PLL synchronizing function.

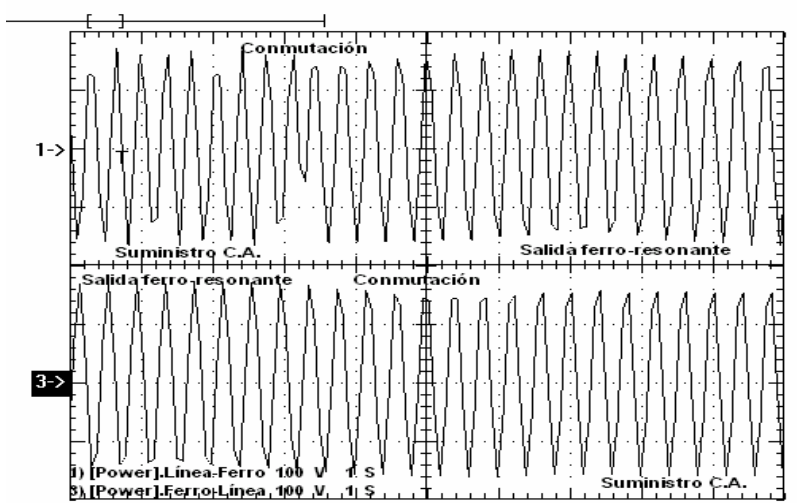

Fig.9 Load voltage transition from inverter drive to AC generator drive (upper trace) and back to inverter drive (lower trace).

\section{CONCLUSIONS}

The preliminary results obtained with the experimental set up using the complete electronic circuitry (power electronic converters and control electronics) prove that the overall concept is correct, that each of the electronic component blocks work as required and that the modular design strategy using different and complementary energy sources, both renewable and traditional, achieve the design aims. The design can be easily adjusted to the use of 12,24 and $42 \mathrm{~V}$ car alternators according to whatever the local supply offers. The use of off-the shell automotive parts widely available in less developed countries in the construction of relatively sophisticated uninterrupted power supplies for critical loads operating in isolated locations is particularly important since it reduces technological dependence and offers equipment that can be locally produced and maintained.

\section{REFERENCES}

[1] F. Avia. "Estado de Desarrollo Tecnológico del Aprovechamiento de la Energía Eólica. Departamento de Energías Renovables". Tecnologías Energéticas e Impacto Ambiental. CIEMAT. Edición 2002. Mc Graw Hill.

[2] S. Martínez. "Sistemas de Alimentación Ininterrumpida (SAI), Estado Actual y Tendencias Tecnológicas". Mundo Electrónico, № 175, Julio 1987.

[3] S. Martínez. "SAI en espera sin tiempo de transferencia". Mundo Electrónico, N 191, Enero 1989.

[4] H. Fernández, V. Guzmán \& M. Giménez. "Design of a Three-Phase UPS Control System Using the Counter Method". IMACS-TC1, Montreal, July 1993.

[5] H. Fernández, A. Martínez, V. Guzmán y M. Giménez. "Sistema de Generación para Turbina de Viento con Alternador de 42V y Regulador Ferroresonante". Seminario Anual de Automática y Electrónica Industrial, Toulouse, Septiembre 2004.

[6] H. Fernández, A. Martínez, V. Guzmán y M. Giménez. "Wind Turbine Generation System Implemented with a Car Alternator for Use in Isolated Locations". International 
Conference on Renewable Energies \& Power Quality, ICREPQ, Barcelona, Mayo 2004.

[7] Fernández H, Martínez A, Guzmán V y Giménez M. "Sistema de Generación para Turbina de Viento con Alternador de 42V y Regulador Ferroresonante". IV Congreso Venezolano de Ingeniería Eléctrica, CVIE, Caracas, Septiembre 2004.

[8] Fernández H, Martínez A, Guzmán V y Giménez M. Aerogenerador Implementado con Alternador de Vehículo para ser Usado en Emplazamiento Aislados. I Encuentro Regional sobre Gestión Energética y Energías Alternativas, Unexpo Puerto Ordaz, Septiembre 2003.

[9] Holt. D. "42V Update". Service Tech. Magazine. September 2001.

[10] R. Walk, R. Kakalec and J. Rootenberg. "An Analytic and Computer Study of the Jump Phenomrnon in Ferroresonant Regulators". IEEE Transactions on Magnetics. September, 1971.

[11] Pacas. J.M. and Schulz M. "Matriz Converter and Convencional Schemes in Rural Power Generation Systems". Siegen, November 2002. 